Br Heart F 1985; 54: 119-20

\title{
Editorial
}

\section{Do we need a new standard for electrocardiographs?}

\author{
RONALD G GOLD \\ From the Freeman Hospital, Newcastle upon Tyme and University of Newcastle upon Tyme
}

Since their publication in 1975 , the recommendations of the American Heart Association Committee on Electrocardiography ${ }^{1}$ have been adopted widely as an unofficial international standard for the performance of electrocardiographs. More recently the draft standard of the International Electrotechnical Commission for performance requirements for single channel and multi channel electrocardiographs ${ }^{2}$ has provided an alternative but again unofficial international standard with which many manufacturers, particularly in Europe, now comply.

One of the main differences between these two standards concerns the specifications laid down for the frequency response of the electrocardiograph. The International Electrotechnical Commission draft demands that the response of the electrocardiograph at $75 \mathrm{~Hz}$ shall be between $71 \%$ and $105 \%$ of the response at $10 \mathrm{~Hz}$ and that between $0.5 \mathrm{~Hz}$ and $60 \mathrm{~Hz}$ the response shall be $90-105 \%$ of the response at $10 \mathrm{~Hz}$. The low frequency performance (below $0.5 \mathrm{~Hz}$ ) is determined by the requirement that after the application of a step function input signal the decay of the recorded amplitude for the first $360 \mathrm{~ms}$ shall not exceed that produced by a time constant of $3.2 \mathrm{~s}$. The American Heart Association specification is somewhat more strict. For the high frequency performance the response at $100 \mathrm{~Hz}$ is specified rather than that at $75 \mathrm{~Hz}$. The amplitude of the electrocardiograph record at $0.05 \mathrm{~Hz}$ must be not less than $70 \%$ of the amplitude at $10 \mathrm{~Hz}$ and should be substantially constant down to a frequency of $0.14 \mathrm{~Hz}$. In neither of these standards is there any reference to phase response.

Tayler and Vincent have drawn attention to the importance of phase linearity at low frequency in the performance of electrocardiographs. ${ }^{3}$ In their care-

Requests for reprints to Dr R G Gold, Cardiology Department, Freeman Hospital, Freeman Road, Newcastle upon Tyne NE7 7DN. fully documented study reported in this issue (p 121) they have shown the artefactual ST changes that can be introduced into the electrocardiogram by a nonlinear phase response. The distortion was greatest in the presence of large $T$ waves and ST segment elevation or depression. Low frequency phase delays produced early ST segment elevation and terminal $T$ inversion in leads with a dominant $S$ wave and horizontal ST depression in leads with a dominant $R$ wave. The changes noted were similar to those seen in disease states and could easily give rise to a false diagnosis of ischaemic heart disease. Furthermore, such changes could be produced by an electrocardiograph that complied with the rigorous American Heart Association frequency response specifications. Now that these phase errors can be substantially reduced by modern filtering techniques, Tayler and Vincent very reasonably suggest that the International Electrotechnical Commission draft specification should be changed to incorporate requirements for phase response.

Many cardiologists are all too familiar with the "built-in ST depression" inherent in the tracings produced by some of the early direct writing electrocardiographs. Tayler and Vincent remind us that less blatant errors may occur with modern equipment and that we still do not have a British standard nor an international standard for electrocardiograph performance. It is 10 years since Krikler and MacFarlane ${ }^{4}$ made a strong plea for a "meaningful international standard" for electrocardiograph performance prepared in consultation with cardiologists and their scientific colleagues. This standard has not yet been forthcoming. The second version of the draft standard on performance requirements for single and multi channel electrocardiographs was considered by a panel of the British Standards Institution in February 1977 and was distributed to the member nations of the International Electrotechnical Commission in June 1978 . Only 14 of the 19 member countries had replied within the six month period given for voting and the 
last reply was not received until October 1979. Eighteen countries voted in favour of the draft but the United States rejected it, the main technical objection being to the less stringent frequency response requirements of the International Electrotechnical Commission document. One negative vote from among the 19 member countries would not have prevented a draft from proceeding to its next stage and at a meeting in Washington of subcommittee 62D of the International Electrotechnical Commission it was agreed that a revised draft would be circulated under the " 2 month procedure."

Meanwhile in 1977 the International Electrotechnical Commission published the first part (general requirements) of its standard for safety of medical electrical equipment. 5 This was subsequently issued as British Standard 5724, part $11979,{ }^{6}$ which is now the recognised official standard in the United Kingdom for the safety of medical and electrical equipment. Part 2 of this standard considers the particular requirements necessary for different groups of medical electrical equipment and several of these particular standards have already been published. The draft standard on the requirements for the safety of electrocardiographs was circulated to national committees in April 1981 for voting on within six months. In June 1981 a meeting of subcommittee $62 \mathrm{D}$ of the International Electrotechnical Commission decided to give priority to the preparation of such particular safety standards, and work on the standard for the performance of electrocardiographs was shelved. The standard for the safety of electrocardiographs was approved by 17 countries but was rejected by the United States and Canada. It was therefore resolved that the particular standard for the safety of electrocardiographs should be published as an International Electrotechnical Commission standard.

At the time of writing the safety standard has not yet appeared and work on the standard for the performance of electrocardiographs, now seven years overdue, remains at a standstill. During this time considerable advances have been made in electronic techniques and the comments of Tayler and Vincent are therefore timely.

Even allowing for the complexities of drawing up an international standard with 19 participating countries, the delay since work on the draft performance standard was started seems inexcusably long. The result is that there is still no British standard for electrocardiograph performance. Perhaps the pursuit of an international standard is utopian. A strong case can be made for a European standard. Channels for the formulation of such a standard already exist in the form of European Committee for Electrotechnical Standardisation (Cenelec) and the technical content of the international draft has already been agreed by all of the member nations from Europe. Although a
British standard is not usually issued until the international counterpart has been published, there is precedent for such a standard to be issued in advance of international publication. Several countries already have their own national standard and a strong case can be made for the early publication of a British standard for performance. This would not preclude revision of such a standard when an international standard is published.

No matter how rigorous the standard for the design and manufacture of an electrocardiograph, the user still largely determines the quality of its performance. Too often deterioration of instruments passes unrecognised and even when electrocardiographs are working properly they may be so misused that a reliable tracing cannot be obtained.

All too often, rather than spend time in relaxing a tense patient, the technician resorts to the use of the filter to provide a tidy looking trace but one in which a small initial $R$ wave can be obliterated, with the result that it is misinterpreted as a QS complex. Although many, but by no means all operators include the calibration signal in the record, it is seldom used as a quick means of checking the frequency response of the machine. If the calibration button is held down for three or four seconds both the high frequency and low frequency responses of the electrocardiograph can be checked.

Despite the absence of an official standard much can be done to raise the quality of electrocardiograph records, both in hospital and particularly in general practice, by regular inspection and servicing of the instruments to ensure that they are still working to the original specification (something which no British standard can ensure) and by proper training of the operator in recording techniques.

\section{References}

1 American Heart Association Committee on Electrocardiography. Recommendations for standardization of leads and specifications for instruments in electrocardiography and vectorcardiography. Circulation 1975; 52 (suppl): 11-31.

2 International Electrotechnical Commission. Draft standard specification for the performance of single and multi-channel electrocardiographs. IEC document 62D (Central Office) 6, 1978.

3 Tayler DI, Vincent R. Artefactual ST segment abnormalities due to electrocardiograph design. $\mathrm{Br}$ Heart $\mathcal{f}$ 1985; 54: 121-8.

4 Krikler DM, MacFarlane PW. Standards for electrocardiographs. Br Heart f 1974; 36: 945-7.

5 International Electrotechnical Commission. Safety of medical electrical equipment, Part 1: General requirements. IEC 601-1 1977.

6 British Standards Institution. Specification for safety of medical electrical equipment. Part 1. General requirements BS5724: Part 1: 1979. 